\title{
DESIGNING KANTIN KEJUJURAN CORNER AT SMP NEGERI 1 KEMANG, BOGOR REGENCY
}

\author{
ANDAYANI, Budi HERMAINI, Dian NOVITA, Monika HANDAYANI, Siti AISYAH \\ Faculty of Teacher Training and Education Universitas Terbuka \\ Email: anda@ecampus.ut.ac.id
}

\begin{abstract}
Located in Tegal Village, Kemang District, Bogor Regency, SMP Negeri 1 Kemang is the only secondary school for the children from the surrounding villages. The local government has the expectation for the school to excel in various aspects, such as to develop the school to be a Secondary School with Exemplary Character. The development of Kantin Kejujuran (lit: Honesty Canteen) is expected to raise the students' awareness of the importance of honesty. The development began in 2017, and it focused on the development of physical facilities. Along such development, initial assessment on the perception of students and teachers towards the value of honesty was conducted using the Likert scale. Open questionnaires were distributed to get the general idea of teachers and students' expectation towards Kantin Kejujuran. In the designing process, it was found that there are similarities between the students' and teachers' perceptions towards the value of honesty, in which it is considered important and needs to be developed. The procedure of using Kantin Kejujuran in accordance with the characteristics of the students needed to be developed from 2018.
\end{abstract}

Key Words: Character, Honest, Kantin Kejujuran

\section{PENDAHULUAN}

Degradasi moral yang saat ini dialami oleh bangsa Indonesia merupakan bentuk kegagalan dalam dunia pendidikan terutama dalam penerapan pendidikan karakter. Pendidikan karakter merupakan tujuan dari Pendidikan Nasional. Seperti yang dijelaskan dalam UU No. 20 Tahun 2003 mengenai Sisdiknas, menjelaskan bahwa "pendidikan nasional berfungsi mengembangkan kemampuan dan membentuk watak serta peradaban bangsa yang bermartabat dalam rangka mencerdaskan kehidupan bangsa, bertujuan untuk berkembangnya potensi peserta didik agar menjadi manusia yang beriman dan bertakwa kepada Tuhan Yang Maha Esa, berakhlaq mulia, serta sehat, berilmu, cakap, kreatif, mandiri dan menjadi warganegara yang demokratis dan bertanggungjawab". Sekolah merupakan salah satu tempat siswa untuk mengembangkan karakter yang diharapkan. Sehingga, sekolah perlu menyediakan fasilitas dan menyusun program kegiatan yang mendorong siswa untuk memperoleh karakter yang diharapkan. Pendidikan karakter tidak hanya melalui pembelajaran dari satu mata pelajaran di dalam kelas tetapi juga kegiatan. 
terintegrasi melalui beberapa mata pelajaran yang diperoleh di dalam dan di luar kelas (Suherman, 2018:2).

Berdasarkan dari hasil wawancara yang dilakukan dengan Pimpinan Desa Tegal Kecamatan Kemang Kabupaten Bogor di ketahui bahwa satu-satunya SMP di Kecamatan Kemang yaitu SMP Negeri 1 Kemang belum melakukan kegiatan yang didesain secara khusus untuk mendorong pembentukan karakter pada sisw a. Hal tersebut juga didukung dari pernyataan Kepala Sekolah SMP Negeri 1 Kemang Bogor yang menjelaskan bahwa 25\% dari guru yang ada belum mendapatkan Pelatihan Pendidikan Karakter, sehingga pembinaan karakter belum diterapkan dengan optimal. Oleh sebab itu diperlukan adanya suatu Program di SMP Negeri 1 Kemang Bogor yang mampu mendorong terbangun dan terbentuknya karakter siswa, khususnya membangun karakter kejujuran. Melalui Kantin Kejujuran, diharapkan secara berangsur-angsur terbangun kesadaran para siswa untuk berperilaku jujur.

Melalui Program Pengabdian pada Masyarakat Fakultas Keguruan dan IImu Pendidikan Universitas Terbuka yang didesain dilaksanakan dalam 3 tahun (2017 - 2019), diharapkan paling tidak warga SMP Negeri 1 Kemang Bogor terutama jajaran Manajer dan para Guru serta juga para Siswa memiliki kesadaran tentang pentingnya karakter jujur untuk berkehidupan dan bermasyarakat.

\section{KAJIAN TEORI}

Pendidikan karakter merupakan pendidikan yang mendorong siswa untuk memiliki perilaku baik. Murphy (1998: 22) menjelaskan bahwa effective character education is based on core ethical values rooted in democratic society, in particular, respect, responsibility, trustworthiness, justice and fairness, caring and civic virtue and citizenship". Dikatakan bahwa pelaksanaan pendidikan karakter yang efektif harus didasarkan atas nilai-nilai inti dari etika yang berkembang dalam masyarakat, khususnya seperti saling menghormati, tanggungjawab, saling percaya, keadilan, serta kepedulian satu dengan yang lain dalam bermasyarakat. Nilai-nilai karakter tersebut semestinya sudah ditanamkan dan ditumbuhkan semenjak dini dalam keluarga dan dilanjutkan dalam lingkungan persekolahan. Dengan demikian, pembentukan lingkungan masyarakat yang berkarakter menjadi perlu diperhatikan untuk menumbuhkan individu-individu yang berkarakter.

Sementara itu, pendidikan karakter bisa dipelajari tidak hanya sebatas mengerti tetapi juga dapat melakukan dan membiasakan. Seperti yang dijelaskan oleh Lickona yang membagi karakter dalam tiga elemen yaitu moral knowing, moral feeling, dan moral action (Sukidjo, Mulyani, Endang, dan Mustofa, 2016). Tersurat bahwa dalam melaksanakan pendidikan karakter secara bertahap nampaknya dimulai terlebih dahulu melalui proses mengetahui, dilanjutkan dengan proses merasakan atau memiliki kesadaran, dan diikuti oleh tingkahlaku berkarakter.

Kejujuran merupakan salah satu karakter dalam kurikulum 2013 yang wajib dikuasai siswa. Jujur adalah perilaku yang didasarkan pada upaya menjadikan dirinya sebagai orang yang selalu dapat dipercaya dalam perkataan, tindakan dan pekerjaan. (Hasan, 2010: 9). Secara sederhana siswa yang memiliki karakter jujur adalah siswa yang mampu memiliki kesesuaian dalam perkataan, tindakan dan pekerjaannya. Kodsinco (d alam Yaumi 2014: 66) menguraikan beberapa hakikat dari kejujuran, sebagai berikut: 
1. Saat perkataan kita benar, maka kita sedang melakukan kejujuran

2. Kita melakukan kejujuran ketika kita bertindak sesuai dengan yang dipikirkan

3. Walaupun orang lain tidak setuju pada saat mengatakan kebenaran, kita tetap jujur menguatarakan kebenaran

4. Hidup dengan kejujuran, akan lebih berbahagia dan dapat membuat bahagia setiap orang di sekitar kita.

Kejujuran dapat mengukur kualitas manusia tersebut sebagai manusia yang beradab. Karena itu, kejujuran sesungguhnya berkaitan erat dengan nilai kebenaran, termasuk di dalamnya kemampuan mendengarkan, sebagaimana kemampuan berbicara, serta setiap perilaku yang bisa muncul dari tindakan manusia (Andayani, 2017: 7-8). Pengetahuan tentang kejujuran sangat sederhana tetapi sulit diterapkan.

Kantin kejujuran merupakan fasilitas yang dapat disediakan sekolah bagi siswa dalam mendorong siswa secara mandiri dan jujur membelanjakan uang sakunya. Kegiatan pada kantin kejujuran dekat dengan keseharian siswa karena siswa bertransaksi secara langsung dalam kantin kejujuran dan mengaplikasikan sikap pada proses transaksi.

Inisiasi Kantin Kejujuran ditujukan untuk melatih siswa berlaku jujur dalam interaksi sosial, termasuk transaksi ekonomi. Jika pada umumnya kantin dijaga oleh petugas khusus yang melayani kebutuhan pembeli, di Kantin Kejujuran tidak ada petugas yang menjaga/melayani siswa dalam membeli dan membayar. Proses transaksi dilakukan secara mandiri oleh siswa. Dilihat dari aspek konsumen, Kantin Kejujuran dapat digunakan sebagai sarana untuk menilai sifat dan perilaku seseorang khususnya sifat religius, kejujuran, kedisiplinan dan tanggungjawab (Sukidjo, Mulyani, Endang, dan Mustofa, 2016).

Tujuan dari Kantin Kejujuran berdasarkan buku panduan penyelenggaraan kantin kejujuran, antara lain sebagai berikut: 1) Melatih peserta didik untuk berperilaku jujur; 2) Menanamkan nilai kemandirian kepada peserta didik; 3) Melatih peserta didik untuk taat dan patuh terhadap norma, tata tertib dan ketentuan yang berlaku baik di sekolah maupun di masyarakat; dan 4) Melatih peserta didik untuk lebih bertanggung jawab dalam setiap tindakan (Puspitasari, 2014).

\section{METODE PELAKSANAAN}

Dalam kaitannya dengan pengembangan desain Kantin Kejujuran sebagai salah satu program Pengabdian pada Masyarakat Fakultas Keguruan dan IImu Pendidikan (FKIP) Universitas Terbuka (UT) di SMP Negeri 1 Kemang Kabupaten Bogor, dilakukan secara bertahap selama 3 tahun. Pada tahun 2017, Kegiatan masih bersifat mencari pola yang sesuai dengan karakteristik para siswa dan terfokus pada melengkapi serta membenahi fisik ruang kantin yang digunakan sebagai Kantin Kejujuran. Melalui kegiatan survey dan diskusi, kantin yang digunakan sebagai Kantin Kejujuran dibenahi untuk kenyamanan dan kebersihannya. Langkah untuk menyiapkan Kantin Kejujuran adalah mencat kembali dinding Kantin sehingga menjadi lebih bersih dan terang. Kemudian, melengkapi ruang kantin dengan meja panjang dan bangku terbuat dari kayu, serta menyediakan wadah makanan yang terbuat dari kaca. 
Selanjutnya, melalui skala likert dijaring informasi te ntang persepsi para siswa dan guru terhadap arti kejujuran. Berikut ini skala likert yang digunakan.

Tabel 1. Skala Likert Persepsi Mengenai Kejujuran

\begin{tabular}{|c|c|c|c|c|}
\hline NO & PERNYATAAN & $\mathbf{S}$ & $\mathbf{N}$ & TS \\
\hline 1 & $\begin{array}{l}\text { Agar hati teman senang, boleh berkata yang melebihi } \\
\text { keadaan sebenarnya }\end{array}$ & & & \\
\hline 2 & $\begin{array}{l}\text { Menyampaikan keterbatasan diri kepada teman akan } \\
\text { mengurangi wibawa }\end{array}$ & & & \\
\hline 3 & Meniru persis pekerjaan teman merupakan hal yang wajar & & & \\
\hline 4. & $\begin{array}{l}\text { Tidak perlu mengakui kesalahan yang tidak disengaja walau } \\
\text { akibatnya bahaya }\end{array}$ & & & \\
\hline 5 & $\begin{array}{l}\text { Agar laporan observasi secara berkelompok bagus, data } \\
\text { yang diperoleh ditambahi dengan data karangan }\end{array}$ & & & \\
\hline 6 & $\begin{array}{l}\text { Meski harus menerima hukuman, mengakui kesalahan } \\
\text { memang harus dilakukan }\end{array}$ & & & \\
\hline 7 & $\begin{array}{l}\text { Menyembunyikan informasi diperlukan untuk melindungi } \\
\text { sahabat }\end{array}$ & & & \\
\hline 8 & $\begin{array}{l}\text { Meskipun dengan maksud baik, berbohong merupakan sikap } \\
\text { yang buruk }\end{array}$ & & & \\
\hline
\end{tabular}

\section{Catatan: $\mathbf{S}$ = Setuju; N= Netral; TS = Tidak Setuju}

Sedangkan kuesioner terbuka berisi 6 (enam) pertanyaan yang disertai pilihan jawaban terbuka, menjaring informasi tentang keinginan dan kebutuhan para siswa dan guru terhadap wujud kantin kejujuran. Kedua instrumen ini dikemas menjadi satu agar para siswa dapat dengan mudah dan cepat mengisi. Dari 100 instrumen yang disebarkan kepada siswa dan 40 kepada guru, yang dikembalikan dan diolah dari siswa sebesar 90 , sedangkan dari guru dikembalikan 16 terisi.

\section{HASIL DAN PEMBAHASAN}

Dari olahan instrumen yang kembali didapat gambaran tentang persepsi siswa dan guru terhadap pengertian kejujuran seperti dipaparkan dalam beberapa chart berikut. 

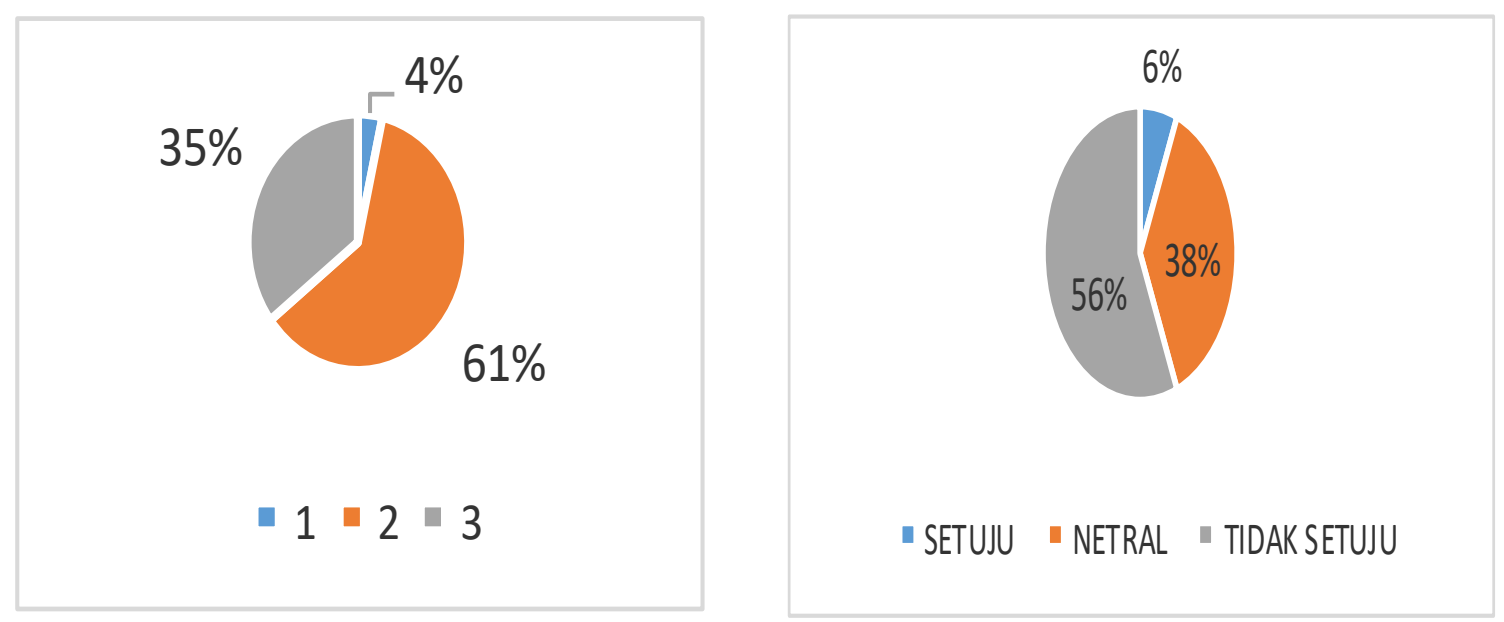

Gambar 1: Meniru persis pekerjaan teman merupakan hal yang wajar

Dari gambar di atas, terlihat bahwa terdapat $61 \%$ siswa dan $38 \%$ guru yang berpersepsi netral apabila menyontek itu sebuah kewajaran. Nampak bahwa mereka sepertinya masih menganggap perilaku menyontek boleh saja dilakukan.Padahal salah satu indikator kejujuran adalah tidak berbuat curang salah satunya dalam hal mengerjakan ulangan tidak menyontek (Elfindri, dkk. dalam Puspitasari, 2014:9). Selanjutnya untuk persepsi siswa dan guru tentang perilaku menyenangkan hati seseorang walau harus berbohong terlihat pada chart berikut:
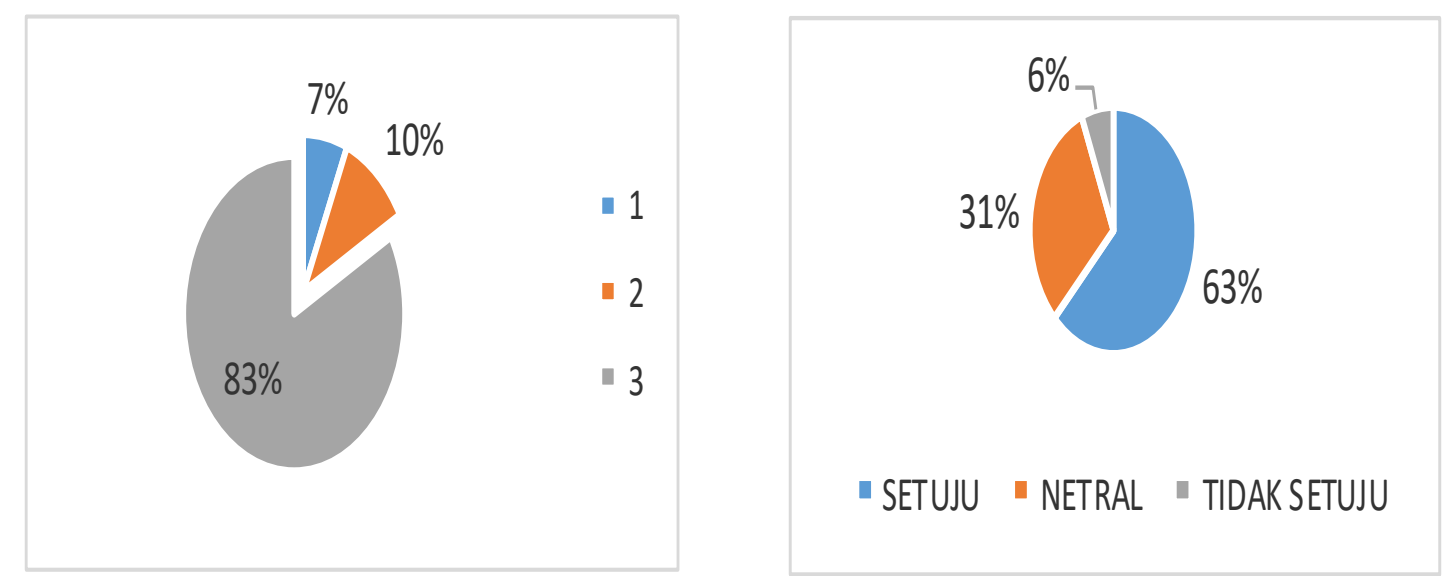

Gambar 2: Berbohong untuk menyenangkan seseorang

Ada $83 \%$ siswa menyatakan tidak setuju jika harus berbohong hanya untuk menyenangkan temannya. Namun, berbeda dengan persepsi $63 \%$ guru yang setuju agar teman menjadi senang, berbohong bisa saja dilakukan. Hal ini wajar dengan melihat perkembangan usia siswa SMP yang remaja dengan usia guru yang sudah dewasa dan lebih mempunyai banyak pengalaman dalam berkehidupan di masyarakat. Sehingga sepertinya para guru lebih memiliki toleransi atas perilaku tersebut dan berpersepsi bahwa perilaku tersebut masih dalam batas dapat diterima oleh masyarakat. 
Sedangkan persepsi siswa dan guru dengan pernyataan agar hasil kerja kelompok menjadi lebih baik, maka boleh saja menambahi dengan data karangan, dapat digambarkan seperti ini.
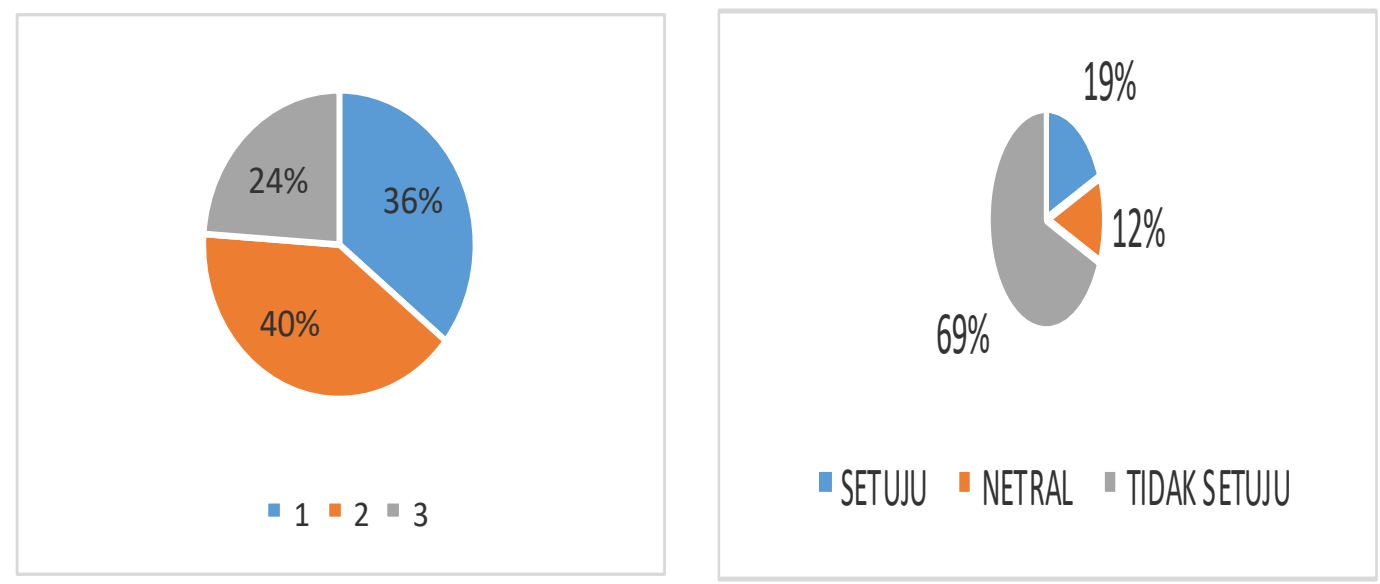

Gambar 3: Data karangan diperbolehkan

Ada $40 \%$ siswa yang netral sedangkan $69 \%$ guru tidak setuju apabila laporan kelompok ditambahi dengan data karangan sehingga menjadi lebih baik.

Sesuai dengan karakteristik perkembangan remaja yang masih dalam usia mencari identitas diri, nampak dari persepsi mereka (66\% dari 90 siswa) yang menyatakan berbohong bukan merupakan perilaku yang baik meski untuk maksud baik, sependapat dengan persepsi 10 guru. Berikut komposisinya.
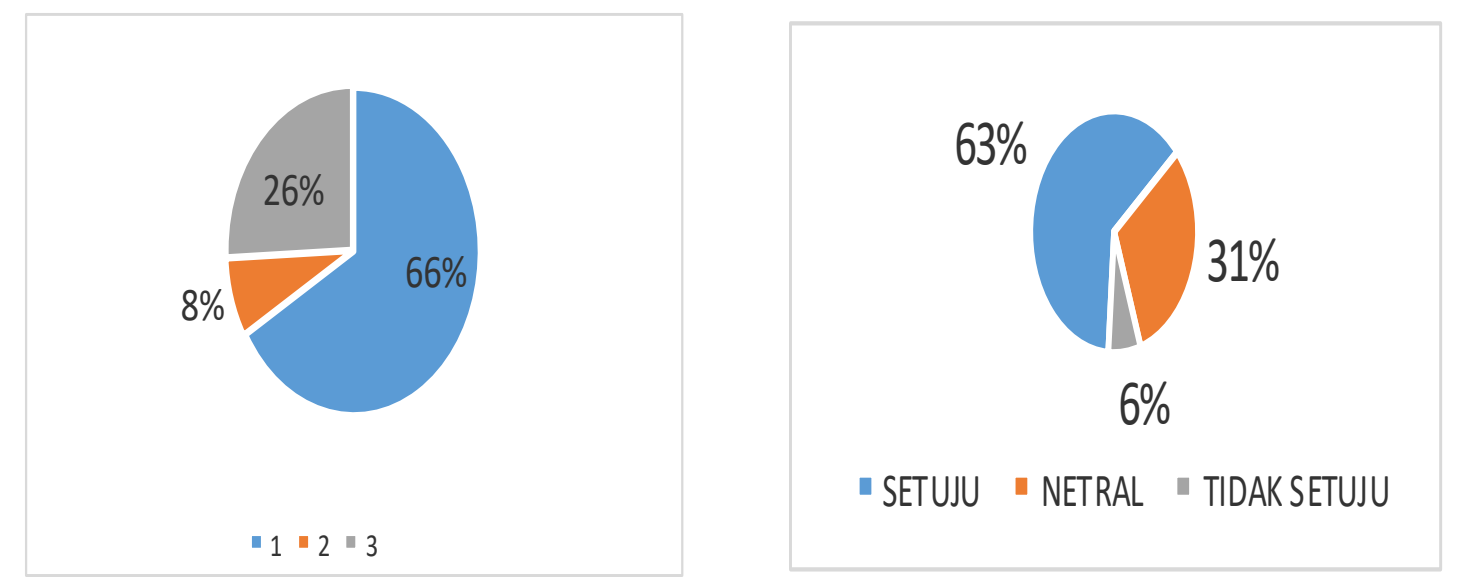

Gambar 4. Persepsi siswa mengenai berbohong bukan merupakan perilaku yang baik

Dengan demikian, dari beberapa gambaran tentang pers epsi siswa dan juga guru terhadap arti kejujuran, nampaknya memang semua tergantung dari nilai-nilai yang telah dimiliki masingmasing mereka yang tumbuh sebelumnya dari lingkungan dalam keluarga dan masyarakat lainnya. Seperti yang disampaikan oleh Szonyi (2014) bahwa Kejujuran itu sesungguhnya perasaan masing-masing individu untuk sejauhmana mengikuti 
Nilai karakter jujur itu sendiri yang berkembang dalam lingkungan mereka. Bisa saja dalam beberapa kejadian akan ada penyimpangan meski sesungguhnya ada keinginan untuk tetap jujur. Hal ini mengisyaratkan bahwa untuk sampai berperilaku jujur secara konsisten akan sangat sulit. Sehingga dalam kasus untuk menumbuhkan karakter kejujuran dalam diri para siswa di SMP Negeri 1 Kemang Bogor bisa jadi membutuhkan waktu yang amat lama.

Selain itu, perlakuan yang diberikan untuk melihat kecenderungan kejujuran para siswa di SMP Negeri 1 Kemang adalah melalui kegiatan jual beli di Kantin Kejujuran tanpa pengawasan. Dengan diberikannya modal untuk pembelian makanan diharapkan modal dana tersebut tetap tersimpan dan tidak berkurang. Menurut salah satu petugas yang diminta untuk mengawasi dari kejauhan, untuk 3 hari pertama modal dana masih utuh. Namun setelah 3 hari modal tersebut makin kecil dan hilang. Hal ini nampaknya merupakan indikasi bahwa perilaku jujur belum populer bahkan sepertinya belum merupakan kesadaran yang harus dimiliki untuk tujuan baik. Fasilitas di Kantin Kejujuran seperti bangku panjang terbuat dari kayu patah karena beban kaki siswa dalam jumlah banyak yang meloncat-loncat di atas bangku panjang. Hal ini juga merupakan indikasi kesadaran untuk memelihara fasilitas umum belum tertanam.

Seperti yang diutarakan oleh Sudrajat (2011: 48) bahwa kebaikan yang diketahui itu berarti bisa mengerti dan membedakan antara baik dan buruk. Berarti pula mengembangkan kompetensi untuk menyimpulkan suatu keadaan dengan sengaja, memilih yang baik untuk dilakukan. Dan, ciriciri tersebut yang belum tumbuh dan berkembang di kalangan para siswa SMP N 1 Kemang Bogor. Banyak faktor yang dapat menjadikan belum tumbuhnya pemahaman dan kesadaran untuk berperilaku baik. Bisa jadi dari lingkungan keluarga dan juga ditambah belum maksimalnya pembinaan di sekolah tentang penanaman nilai-nilai karakter yang baik.

Selanjutnya, dari kuesioner terbuka yang diisi oleh siswa dan guru tentang harapan dan keinginan mereka untuk mengisi kantin kejujuran, rata-rata mereka menginginkan jenis makanan yang murah tetapi membuat kenyang. Selain itu juga mereka setuju jika ada kepengurusan dan mekanisme yang baik untuk memelihara kantin kejujuran.

\section{SIMPULAN}

Dari hasil pengembangan kantin kejujuran di SMP N 1 Kemang Bogor pada tahun 2017, dapat disimpulkan bahwa pada umumnya siswa dan guru mempunyai persepsi mirip tentang arti kejujuran. Namun bertolak belakang dengan persepsi para siswa, ternyata masih dibutuhkan upaya yang keras untuk menumbuhkan perilaku jujur dan baik.

Dengan demikian, pengembangan kantin kejujuran pada tahun 2018, dibutuhkan penambahan fasilitas serta penataan sudut kantin kejujuran yang lebih baik agar siswa secara jelas mengetahui maksud dan makna kantin kejujuran. Bahwasanya kantin kejujuran bukan hanya sekedar untuk membeli makanan, namun lebih dari itu, untuk melatih kesadaran dan perilaku jujur terutama di kalangan para siswa. 


\section{REFERENSI}

Andayani, Tri Rezeki (2017). Model Pembelajaran Nilai Kejujuran Melalui Budaya Malu pada Anak Usia Sekolah Dasar (Suatu Alternatif Pendidikan Karakter). Dikutip dari http://repositori.perpustakaan.kemdikbud.go.id/208/1/trirejekiandayani_HASIL\%2OPER BAIKAN.pdf. Pada tanggal 10 Agustus 2018.

Hasan, Said Hamid (2010). Pengembangan Pendidikan Budaya dan Karakter Bangsa. Jakarta: kementerian Pendidikan Nasional, Badan penelitian dan Pengembangan Pusat Kurikulum.

Murphy, M. (1998). Character Education in American's Blue Ribbon Schools. Lancaster, P.A.:Technomic Publishing.

Puspitasari, Noviana Ayu (2014). Implementasi Sikap Jujur melalui kantin Kejujuran pada Tiga Sekolah Dasar di Wilayah Purwokerto. SKRIPSI. UMP. Diunduh dari http://repository.ump.ac.id/206/3/BAB\%20II_Noviana\%20Ayu\%20P..pdf Diunduh pada tanggal 21 Oktober 2018

Sudrajat, Ajat (211). Mengapa Pendidikan Karakter? Jurnal Pendidikan Karakter, Tahun I, Nomor 1, Oktober 2011, halaman 47 - 58. Universitas Negeri Yogyakarta. Diunduh dari http://download. portalgaruda.org/article. php?article=102395\&val=436\&title=MENGAPA \%20PENDIDIKAN\%20KARAKTER? Pada tanggal 10 Agustus 2018

Suherman, A. (2018). The implementation of character education values in integrated physical education subject in elementary school. Paper presented at the , 42 doi:http://eresources.perpusnas.go.id:2141/10.1051/shsconf/20184200045 Retrieved from https://e-resources. perpusnas.go.id:2057/docview/2038293920?accountid=25704

Sukidjo, Mulyani, Endang, dan Mustofa. (2016). Warung kejujuran sebagai sarana pendidikan karakter bagi mahasiswa Fakultas Ekonomi UNY. Dikutip dari http://eprints.uny.ac.id/41228/1/03\%20Sukidjo.pdf diakses pada 10 Agustus 2018

Szonyi, G. (2014). Challenges of honesty*. American Journal of Psychoanalysis, 74(4), 340-8. doi:http://e-resources.perpusnas.go.id:2141/10.1057/ajp.2014.27

Yaumi, Muhammad. (2014). Pendidikan Karakter Landasan, Pilar dan Implementasi. Jakarta: Prenadamedia Group 